\title{
Using Alternative Assessments In Business And Foreign Language Classes
}

Deborah Gill, Pennsylvania State University, USA

Diane Lucas, Pennsylvania State University, USA

\begin{abstract}
The present study will be divided in three parts: (1) a discussion of authentic alternative assessments vs. traditional assessments in language and business classes; (2) an explanation on how to create authentic alternative assessments using technology-based and non-technologybased materials; and (3) tools to evaluate these authentic assessments.

We will discuss alternative assessments which have been used in a number of different business and foreign language classes, student reactions to these assessments, and our observations as to the impact and results these assessments have had on student learning.
\end{abstract}

Keywords: Alternative Assessment; Business; Foreign Language; Technology-Enhanced Assessments; NonTechnology-Enhanced Assessments

\section{INTRODUCTION}

electing the most appropriate evaluation method for classrooms and programs can be daunting, especially when deciding between traditional paper-and-pencil tests with multiple choice, fill-in-the-blank, matching, true-false, etc. and innovative, alternative assessments such as project- and/or performance-based assessments, portfolios, conferencing, learning logs or blogs, virtual learning environments, etc., to name a few. The present study will begin with a brief review of the literature with regard to alternative assessments. We will then compare alternative assessments to traditional assessments within business and foreign language classes. Next, we will discuss alternative assessments within these same two disciplines, providing an explanation on how to create assessments, concrete examples, and a qualitative analysis of student reaction. Finally, we will discuss methods of evaluation as well as the impact and results on student learning.

The term "alternative assessment" has been referred to in the literature by many different terms: performance assessments, authentic assessments, situational assessments, and portfolio assessments, just to name a few. These terms share a basic principle: they are assessments which substitute for traditional and standardized testing and the problems associated with them while at the same time examining a student's performance on different real life tasks. These assessments are used within the classroom context and can be intertwined seamlessly into the daily activities of the classroom. For purposes of the present study, we will provide a brief review of the literature relating to project-based assessments as well as authentic and situational (or task-based) assessments.

The main goal of alternative assessments is to "gather evidence about how students are approaching, processing, and completing real-life tasks in a particular domain” (García and Pearson, 1994, p. 357). One such type of alternative assessment is project-based assessments. According to Thomas (2000), there are five criteria which distinguish project-based assessment from other types of alternative assessments:

- $\quad$ Projects are central, not peripheral to the curriculum;

- $\quad$ Projects are focused on questions or problems that drive students to encounter (and struggle with) the central concepts and principles of a discipline;

- $\quad$ Projects involve students in a constructive investigation; 
- $\quad$ Projects are student-driven to some significant degree; and

- $\quad$ Projects are realistic, not school-like

(Thomas, 2000, pp. 3-4)

Included in these are performance assessments, authentic assessments, situational assessments, portfolio assessments, etc. A number of these assessments will be discussed briefly when discussing the use of alternative assessments in language courses.

\section{ALTERNATIVE ASSESSMENTS VS. TRADITIONAL ASSESSMENTS}

\section{A. Business Courses}

With an emphasis on student-centered learning and incorporating materials and methodologies which will provide a student an opportunity to experience the business world before graduating, alternative assessments have taken the place of traditional assessments in a number of business courses. Traditional assessments (i.e., exams) provide a benchmark of learning for particular skills, i.e., the ability to define terms that apply to their discipline, such as general marketing, demographics, marketing, ROI, etc. A standard test bank examination provides students with a myopic approach to learning, providing only one possible solution to a specific problem or questions. However, they do not provide simulated, real life experiences; the alternative assessments incorporated within business courses at Penn State University, DuBois serve this purpose through project-based assessments.

Project-based learning allows for cognitive learning skills to be employed. Project-based learning allows students to be assessed via a project that allows them to bring knowledge from their core business courses to a more comprehensive learning assignment. The goal of the project-based assignment is to have students retain not only the concepts learned in the course, but also to stimulate an overall sense of learning by bringing into the project all of the knowledge acquired in their discipline up to this particular point in time. This knowledge is more easily retained by the students, as shown by the examples that follow in the following section.

When an alternative assessment is given to students, they must take the terms and concepts learned (i.e., what would be "tested" on a traditional test) and apply them. Students are asked to begin research that will lead them to completion of their final project. As they begin to research and complete the required assignments, this allows for communication and interaction to begin between the student and instructor. Students provide justification as to why they answer the project requirements in the manner that they do through a combination of prior subject matter knowledge and solid research.

\section{B. Language Courses}

Learning a second language is more than just learning set vocabulary words and how to conjugate a verb, which in itself is difficult for non-native speakers of Spanish. Traditional assessments in second language learning allows a student to demonstrate a mastery (or not) of specific vocabulary words, grammar points, and cultural information which has been presented in a textbook or within a classroom. These tests might be a combination of translation English/Spanish-Spanish/English, fill-in-the-blank from a word bank, provide the correct verb form of a given verb, and provide cultural information requested. Generally these assessments are void of context (i.e., are unrelated individual sentences/phrases) and are rote memorization.

Traditional assessments in second language learning provide only a sampling of what a student has been able to memorize and "does not provide insight into how students would perform on truly 'worthy' intellectual tasks" (Worthen, 1993, p. 445). In real life, when trying to communicate in a second language, students do not have fill-in-the-blank or multiple choice options, nor do they have a word bank to choose the correct word; they must be able to demonstrate the ability to use the language and understand the cultural context of the exchange. Therefore, in order to truly observe a student's acquisition of a second language (and culture), alternative assessments must be incorporated so that "student learning can be better assessed by examining and judging a student's actual (or simulated) performance on significant, relevant tasks" (Worthen, 1993, p. 445). These alternative assessments provide an opportunity to focus on process, product, and performance. How this is done through alternative assessments will be discussed below for second languages. 


\title{
III. USING ALTERNATIVE ASSESSMENTS
}

\author{
A. Business Courses \\ 1. Examples of Alternative Assessments
}

Because of space limitations, we will briefly discuss two courses in which project-based assessments are routinely used, Business Administration 250 and Business Administration 421.

Business Administration 250 is Small Business Management and is a course which some students take during their final semester of the two-year Business Program (similar to a capstone course), but more frequently is taken during the second semester of one's junior year. During this course, students are expected to complete a series of worksheets which function as guidelines for research in their specific industry. With these completed worksheets, students are then required to develop a final business plan. This business plan must be completed at a level suitable to present to a financial institution or investor as a plea for funds.

A second business course which incorporates project-based learning is Business Administration, Project Management and Planning for Business. This is a senior-level course which is generally taken the semester immediately proceeding a student's last semester, in which a student does an internship. In this course, students learn project management theory through a series of in-class lectures. The information which they learn from these lectures are then put into practice through higher level thinking skills as the project takes on a real life. The rubric which students are given in advance (see Appendix 1 for an example) provides students with guidance as to what is important when planning a project.

Many of the projects which students choose to undertake are real life business projects useful for a business within the community. One such project focused on a business' waste of food. The student researched the company, discussed the project and used available software to define the scope of the project. The student then broke down the tasks into a manageable structure, organizing and analyzing the problem piece-by-piece. When the project was completed, not only had the student completed a satisfactory project plan for this company, the employer reaped the benefits of a more stream-lined process through incorporating the recommendations into the daily running of the business and the student received a promotion to management as a result of his project-based assignment.

\section{2. $\quad$ Creating Alternative Assessments}

When creating alternative assessments for business courses, it is key to use core terms, concepts, and theories of a particular discipline as the foundation. From there, a set of defined exercises can be created to build on each of those concepts and theories, with these exercises forming the guidelines for the project-based assessment and the construction of the final projects. Each assignment throughout the semester can be considered a "map" that will lead the student to their final goal.

\section{Student Reactions to Alternative Assessments}

Project-based assessments have been used in the BA 250 and BA 421 courses for the past three years. During that time, student reactions have been measured through the use of peer evaluations of each project to see whether or not they would invest in the start-up business which was proposed. The reactions to these projects overall has been positive, with many of the proposed projects being well-received by the students' peers. Several of the students have also started their own businesses based upon their final business plans.

The student reactions to project-based assessments in the BA 421 courses have been extremely positive and successful. Students present their final projects to not only their peers in the course but also to employers. The success of these projects has been seen through (1) a number of employers purchasing the project management software that the student has developed and (2) students who have received promotions in their current jobs, promotions which were based upon the project that they developed for the course and then presented to their current management. 


\section{B. Language Courses}

\section{Examples of Alternative Assessments}

A discussion of the use of project-based assessments for business courses was presented previously. In second language learning, it is imperative to provide opportunities to students which are as authentic as possible within a classroom setting. In the second language classroom, we will discuss the use of authentic alternative assessments. We will define an authentic alternative assessment as "a situational activity in which students demonstrate the ability to use written and/or oral language within real-life (or simulated real-life) situations, within specific contexts, and for specific purposes".

Our target population is students who are novice-to-intermediate second language learners, i.e., those who are in the first three semesters of their language learning. The final goal is to have students, by the end of their third semester, have proficiency in reading, writing, speaking and listening, at the advanced-high to novice-low level on the American Council on the Teaching of Foreign Language (ACTFL) guidelines ${ }^{1}$. Therefore, to move students towards this goal, a move away from traditional testing to authentic alternative assessments was made. Examples of these assessments include:

- $\quad$ Situational assessments in which students are given a real-life situation (i.e., meeting a student from another country and discussing a custom or tradition with that student);

- Project-based assessments in which students are given a specific task to complete (i.e., creating a brochure for Spanish speakers who will be visiting for a month and know nothing about the customs and traditions of the community); and

- $\quad$ Performance assessments in which students participate in a real-life situation (i.e., video conferencing with native speakers from another country [real life] or reporting news from a Spanish speaking country [simulated real life]).

Second language learning is a combination of language learning (i.e., vocabulary and grammar) as well as cultural competence (i.e., learning the customs, traditions, and idiosyncrasies of a region). Therefore, alternative assessments can be woven seamlessly into the curriculum as they are based on daily classroom activities. Nongraded situations, projects, and performances lead to final, graded assessments throughout a semester. Two examples of authentic alternative assessments can be found in Appendix 2.

\section{2. $\quad$ Creating Alternative Assessments}

The creation of authentic alternative assessments in second language learning is a seamless process as language learning lends itself to the use of language in authentic and real-life situations. As one prepares to create an authentic alternative assessment, it is necessary to decide what the ultimate goal is for our students to accomplish. This goal can be determined through a review of one's curriculum.

Many Spanish programs have specific objectives and goals which are to be met at a certain level. Whether or not a textbook is used, those objectives and goals are stated in some way. The present discussion will take as a premise that a textbook is used in the curriculum, more specifically, the book ¿Sabias que...? (VanPatten, 2008). This textbook promotes a task-based approach, which lends itself easily to the use of authentic alternative assessments. Creating alternative assessments require the following components:

- $\quad$ State the objectives and goals for the task;

- $\quad$ Provide "mini-tasks" which lead to the final goal (i.e., if the final goal is giving a party, the mini-tasks might be (1) creating a grocery list, (2) preparing invitations, (3) deciding on activities, etc.); and

- When introducing the assessment, provide students with the expectations for the assessment (i.e., how will they be evaluated).

\footnotetext{
${ }^{1}$ Because of space limitations, we will not discuss here what the characteristics of these levels are. For more information, please see the ACTFL website at http://www.actfl.org.
} 
Most importantly, "valid assessment depends on all those involved in the assessment understanding the rules of the game" (Spence-Brown 2001, p. 478). Students must understand what is expected of them in order to be able to perform the ultimate assessment.

In order to create an authentic alternative assessment, the goals and objectives for the entire lesson should be used to accomplish the ultimate goal. Each chapter in ¿Sabias que...? is divided into three sections, each one focusing on specific vocabulary and grammar points and building on one another. Using the general concept of a section, a number of authentic assessments (tasks) are created, with students being encouraged to use real-life language and building on the drill-and-kill practice of grammar and vocabulary which is completed outside of class. At the end of a lesson, a final authentic alternative assessment is given in which students incorporate everything they have done in the lesson in a simulated, real-life situation, such as that provided in Appendix 2. As Wiggins (1989, p. 711) states, "Authentic tests are not needlessly intrusive, arbitrary, or contrived merely for the sake of shaking out a single score or grade. Instead, they are 'enabling'-constructed to point the student toward more sophisticated and effective ways to use knowledge". Therefore, authentic alternative assessments are created with the purpose of allowing students to demonstrate what they know and can use rather than on what they have memorized and can regurgitate back to a specified set of vocabulary words and grammar points.

\section{3. $\quad$ Student Reactions to Alternative Assessments}

Authentic alternative assessments have been incorporated in Spanish language classes at Penn State DuBois through real life situational activities for the past three years. During that time, student reactions have been measured through the use of open-ended questions as well as likert-scale class evaluations. The reactions to these projects overall has been positive (i.e., "I actually had to use my Spanish! It was cool!"; "It's hard to use my Spanish, but I was surprised that I could do it!").

Not all of the reactions were positive, however. Negative reactions included comments such as "I know the vocabulary, but I can't use it! It's too hard!" and "I'm never going to use my Spanish anyways, so why should I have to use it?" These comments were not unexpected as, unlike the Business students who are provided with activities that they will use in their everyday life and because they are taking the courses as part of their major curriculum, most of the students who are taking Spanish are taking it only because "it is a requirement" and not because it constitutes part of the major. Therefore, not all students want to have to put more than a minimal effort into studying Spanish.

\section{EVALUATION OF ALTERNATIVE ASSESSMENTS}

\section{A. Business Courses \\ 1. Evaluation Methods for Alternative Assessments}

When implementing project-based assessments in courses, it is extremely important to provide students with a rubric which sets out from the beginning the expectations for the final project goal. These expectations will vary for each course, based upon what the goal is for that course.

Appendix 1 provides the rubric for BA 250 (Small Business). The project is based on 200 points, broken down in three parts: (1) Style and Appearance, (2) Grammar and Spelling, and (3) Content (Executive Summary, the Final Plan, and the Content itself). The first two parts make up only a small portion of the 200 points (65 points total), but at the same time a sufficient number for students to understand that in the business world it is important to have a clean and professional appearance. The third section, Content, is broken down into three different areas, with each area defined thoroughly so that students can use a checklist to make sure that their business plans for a start up business are complete and well thought out.

Appendix 3 provides the rubric for BA 421 (Project Management). The rubric for this course is distinct from that of BA 250. Different from BA 250, BA 421 has a final objective of completion of a project for improvements to an existing company, either to remedy an existing problem (i.e., food waste) or to improve a 
component of a company to increase productivity, sales, etc. Therefore, the rubric for this project is based upon organization and implementation of the project, including specific starting and ending dates, specific tasks which need to be initiated and completed, etc. Students receive a specific number of points for each detail, where in the BA 250 course the grade was more global in the area of "content".

\section{Impact and Results on Student Learning}

The impact on student learning in the two courses under discussion has been impressive. Over a two-year period, students have received the alternative assessments with a greater sense of accomplishment than a traditional form of assessment. Students are able to retain the concepts and theories covered in the courses with a deeper sense of understanding. This is demonstrated through students who have had their employers adopt a particular model or approach to certain business problems. In other instances, students have formed their own small businesses as a result of researching their industry and formulating a formal business plan. Finally, the impact can also be noted through those students who have received promotions to management due to their project management knowledge.

\section{B. Language Courses}

\section{Evaluation Methods for Alternative Assessments}

Evaluation of authentic alternative assessment should be well-thought-out, with the student understanding how he will be evaluated before beginning the tasks. Designing and implementing authentic tasks and assessments takes time and the evaluation of those tasks is not easy. The use of specific evaluation criteria is imperative and has a positive impact on instruction itself. If the evaluation criterion is provided to students in advance, the quality of the outcome will increase (Montgomery 2002). Figure 1 (modified from Scott and Rodgers 1993 and cited in Montgomery 2002, p. 36) provide the grading criteria for a writing activity in a Spanish 1 class:

\footnotetext{
Sobresaliente (16-20 points)

There is evidence of connected, organized discourse with some evidence of fluency of expression. The information presented about Madrid is accurate and plausible. The topic is thoroughly and logically developed with ideas clearly stated. An attempt at more complex structures and vocabulary may be evident, with some errors. There are almost no errors in agreement, word usage, or language mechanics.
}

Notable (11-15 points)

The letter is limited in topic development, somewhat choppy, and loosely organized. The information presented about Madrid is mostly accurate. Sequencing is logical but may be incomplete with some errors in word choice or usage. The meaning is clear, but there may be errors in agreement or syntax. Occasional errors in spelling. Communication is hampered by interference from English.

\section{Bien (6-10 points)}

The letter demonstrates a notable lack of fluency with inadequate development of the topic. Ideas are confused, with a lack of logical sequencing, limited vocabulary, and frequent errors in spelling, agreement, and mechanics of language. The information about Madrid is largely invented and limited. Meaning may not be clear, and there is evidence of interference from English.

\section{Mención Honorífica (1-5 points)}

The letter is not substantive, or there may not be enough to evaluate. There is no evidence of organization of thought and almost no information on Madrid is present. Errors dominate, and the letter does not communicate meaning. Lack of control of the language is evident.

Figure 1. Rubric for Spanish 001

Figure 1 provides students with the guidelines on exactly how the authentic alternative assessment will be evaluated. Writing a letter is a real-life task and the inclusion of cultural information about Madrid provides authenticity to the task. Therefore, students understand exactly what is expected of them with regard to both process and product, or form and content as is used in courses at Penn State DuBois. 


\section{Impact and Results on Student Learning}

The impact on student learning has been noticeable. Through the use of authentic alternative assessments, students must take responsibility for acquiring the language rather than only memorize vocabulary and grammar to be able to answer discrete point tests.

In order to compare student performance on discrete point tests to the use of authentic alternative assessments, for each lesson, two groups of students with similar backgrounds (i.e., students in beginning and intermediate Spanish classes who are non-native speakers of Spanish) were used. In one group, the experimental group, students were presented with authentic tasks during class time and were given "homework assessments" (done in a controlled setting where books, notes, etc. cannot be used, but outside of class time) and "authentic alternative assessments" (done during class time, at the end of a lesson where authentic tasks have been incorporated to learn the material). In the second group, students were taught through traditional methods (i.e., using the textbook, teacher driven activities) and were given discrete point, traditional tests as their principle assessment and were given the authentic alternative assessments as a culminating activity which did not have a great impact on student outcomes (although students did not know this so students would perform the assessment to the best of their abilities).

The preliminary results show that the students in the control group (i.e., a "traditional" methodology) and the students in the experimental group (i.e., the group using authentic tasks leading up to the culminating authentic alternative assessment) performed similarly on the traditional assessments, while the students in the experimental group significantly outscored students in the control group on the authentic alternative assessments. Figure 2 below shows the comparison of the two groups.

\begin{tabular}{|c|c|c|c|c|}
\hline \multicolumn{5}{|c|}{ Spanish 1} \\
\hline Lesson & \multicolumn{2}{|c|}{ Homework } & \multicolumn{2}{|c|}{ Authentic Alternative Assessment } \\
\hline & Control (\%) & Experimental (\%) & Control (\%) & Experimental (\%) \\
\hline LP & 84 & 82 & 76 & 90 \\
\hline L1 & 78 & 79 & 74 & 87 \\
\hline $\mathrm{L} 2$ & 83 & 82 & 77 & 86 \\
\hline L3 & 74 & 72.5 & 72 & 83.5 \\
\hline L4 & 82 & 83.5 & 75 & 87 \\
\hline L5 & 83 & 83 & 77 & 86 \\
\hline \multicolumn{5}{|c|}{ Spanish 2} \\
\hline Lesson & \multicolumn{2}{|c|}{ Homework } & \multicolumn{2}{|c|}{ Authentic Alternative Assessment } \\
\hline & Control (\%) & Experimental (\%) & Control (\%) & Experimental (\%) \\
\hline L6 & 82 & 83 & 73 & 86 \\
\hline L7 & 85 & 82 & 73 & 87.5 \\
\hline L8 & 84.5 & 84 & 75 & 84.2 \\
\hline L9 & 81 & 83 & 72 & 89 \\
\hline L10 & 86 & 83 & 70.5 & 86.5 \\
\hline L11 & 83 & 82.5 & 72 & 82 \\
\hline
\end{tabular}

Figure 2. Comparison of Results on Student Learning

Figure 2 shows that, on traditional tests, there is no significant difference in student performance connected to the type of input the students received. However, the results are significant when students are given authentic alternative assessments. The control group consistently scored lower on the alternative assessments in which they were required to use the language in real-life situations. Although these results are only of a pilot group of students, indications are that students who use alternative assessments to learn a language appear to be able to use the language in real life situations better than students who do not. Research is continuing to this end.

\section{CONCLUSIONS}

We have provided here a brief description of the use of a number of different types of alternative assessments in business and foreign language classes. Through the use of project-based assessments in business 
courses, students have demonstrated an ability to propose small business start up plans which have led to the opening of small businesses. They have also demonstrated an understanding of the concepts and theories of project management through the ability to develop plans to improve productivity and/or implement new ideas to increase production. Student reactions to these project-based assessments have been positive, with a number of students opening their own small businesses or being promoted to managerial positions within a company they presently work.

With regard to language learning, authentic alternative assessments have provided students with the opportunity to demonstrate true language acquisition through their ability to participate in situations, complete projects in the second language, and be able to perform tasks with native speakers of the second language. As Huerta-Macías (1995, p. 9) states, "Alternative assessment provides a menu of possibilities, rather than any one single method for assessment. Student growth can be more reliably assessed because information from various sources is included in the process". As the initial results above have shown, student performance on authentic alternative assessments have shown that students perform better on these assessments, which allow the opportunity to use real language, than they perform on standard, traditional tests.

\section{AUTHOR INFORMATION}

Dr. Deborah Gill is an Associate Professor of Spanish at the Pennsylvania State University, DuBois campus, where she teaches undergraduate Spanish language and culture courses, as well as Women's Studies and the Capstone course for the four-year Letters, Arts and Sciences degree. She received her Ph.D. in Hispanic Applied Linguistics from the University of Southern California. Her primary research interests include language variation, languages in contact, second language acquisition and assessment, and the use of technology and authentic assessments in teaching. E-mail: djg25@psu.edu (Corresponding author)

Ms. Diane Lucas is the Coordinator of Administrative Support Systems for Information Technology Services and an Instructor of Business at the Pennsylvania State University, DuBois campus, where she teaches business and management information systems. She received her Master's Degree in Technology Management from the University of Maryland, University College. Her primary research interests are in project and organizational management. E-mail: $\underline{\text { dll150@ @su.edu }}$

\section{REFERENCES}

1. Anderson, Rebecca S. (1998). Why Talk About Different Ways to Grade? The Shift from Traditional Assessment to Alternative Assessment. New Directions for Teaching and Learning, 5-16.

2. Bachman, Lyle F. (2002). Alternative Interpretations of Alternative Assessments: Some Validity Issues in Educational Performance Assessments. Educational Measurement: Issues and Practice, 5-18.

3. García, G.E. and Pearson, P.D. (1994). Assessment and diversity. In L. Darling-Hammond (Ed.), Review of research in education (pp. 337-391). Washington, DC: American Education Research Association.

4. Huerta-Macías, Ana. (1995). Alternative Assessment: Responses to Commonly Asked Questions. TESOL Journal, 5(1), 8-11.

5. Montgomery, Kathleen. (2002). Authentic Tasks and Rubrics: Going Beyond Traditional Assessments in College Teaching. College Teaching, 50(1), 34-39.

6. Scott, R. and B. Rodgers. (1993). Assessing communication in writing: The development of a Spanish writing context. Foreign Language Annals 26(3), 383-392.

7. Spence-Brown, Robyn. (2001). The eye of the beholder: authenticity in an embedded assessment task. Language Testing, 18(4), 463-481.

8. Thomas, John W. (2000). A Review of Research on Project-Based Learning. San Rafael, CA: The Autodesk Foundation.

9. Wiggins, Grant. (1989). A True Test: Toward More Authentic and Equitable Assessment. The Phi Delta Kappan, 703-713.

10. Worthen, Blaine R. (1993). Critical Issue That Will Determine the Future of Alternative Assessment. The Phi Delta Kappan, 74(6) [Feb., 1993], 444-448, 450-454. 


\section{APPENDIX 1: GRADING RUBRIC FOR BA250 SMALL BUSINESS}

Possible Points 40 Component: Style \& Appearance:

Organized Writing Flow

Neat, Appealing to the Eye

YOUR TOTAL POINTS FOR THIS SECTION:

Possible Points 25 Grammar \& Spelling:

Sentence Structure/Word Choice

\section{YOUR TOTAL POINTS FOR THIS SECTION:}

135 Points for Content

Breakdown of Content:

Possible Points 20 Total for Executive Summary which include:

10 Completeness

10 Does it entice me to read further?

Possible Points 15 Total for Financial Plan which include:

5 Financial Assumptions

10 Accuracy \& Completeness

Possible Points 100 Total for Remaining Content:

Does it Contain?

Vision

Mission Statement

Company Goals \& Objectives

Industry Analysis

SWOT

Business Strategies

Legal Structure

Company/Product Overview

Marketing Plan Overview

Market Analysis

Marketing Strategy

5 Items of Market Research (Work Cited Page)

Supporting Documents

TOTAL SCORE out of 200 possible points 


\section{APPENDIX 2: AUTHENTIC ALTERNATIVE ASSESSMENTS FOR SPANISH COURSES}

\section{Example 1: Spanish 001 \\ Lección 1 (Oral Assessment)—Example of A Performance Assessment (Simulated, Real-Life)}

You have received a video from your friend in Spain that you are collaborating with! He tells you that he enjoyed your video that you sent to him a couple of weeks ago! And, he can't wait to hear more about you!

Today you are going to send him a video recording! He would like to know what you do during the week (Monday through Friday). Explain to him what you do during the week, including such things as what time you generally get up in the morning, when you go to bed, when you arrive at school, when you have classes, when you have lunch. If you don't have school, tell him you have a free day (un día libre). Then, before saying good-bye and finishing your video, ask him three questions about his schedule. Then finish your video.

Your grade will be based on form and content.

\section{Example 2: Spanish 001}

Lección 1 (Written Assessment)—Example of a Situational Assessment (Simulated, Real-Life)

You have been in school for three weeks now and it's time to write your weekly letter to your mom! Since you are now settled into classes, you decide that it would be nice to tell her about your schedule!

Tell her about your weekly routine. Tell her what times you generally get up during the week (MondayFriday-if it depends on the day, tell her the different times), what time you go to school, what classes you attend (and the times) each day (if you have a MWF class, you can put those together as one; same with a TR class), when you have lunch, when you go home, and when you go to bed. If you have a free day (or free days), tell her that too (free day = un día libre). Start with "Querida mamá" and end with "Besos".

Your grade will be based on form and content. 


\section{APPENDIX 3: GRADING RUBRIC FOR FINAL PROJECT OF BA421}

15 Points: Clear and logically organized. The audience can follow your line of reasoning for your WBS.

15 Points: Print a report of your choice on paper to hand to the instructor of the day or your presentation. Use this report in your presentation (think creatively).

10 Points: Complete explanation of Project.

30 Points: All task relationships are logical and span a series of days.

20 Points: Appropriate resources are assigned to the proper logical tasks.

20 Points: At least 3 tasks show a form of lag and/or lead time.

10 Points: All task duration estimates (?) are removed from the project. And task durations make logical sense.

10 Points: Project Calendar is correctly assigned.

5 Points: The project has a definite beginning and an ending date.

5 Points: Percentage complete in at least 3 tasks. 


\section{NOTES}

